\title{
Well-to-seismic tie of Amangihydrocarbon field of the Niger Delta of Nigeria
}

\author{
Sonny Inichinbia ${ }^{1}$, Peter O. Sule ${ }^{2}$, Aminu L. Ahmed ${ }^{2}$ andHalidu Hamza \\ ${ }^{I}$ Department of Physics, Ahmadu Bello University, Zaria, Nigeria \\ ${ }^{2}$ Department of Geology, Ahmadu Bello University, Zaria
}

\begin{abstract}
In this paper we performed seismic-to-well tie and wavelet extraction that would subsequently be used for inversion. We took cognizance of the key factors that make for accurate well-to-seismic tie and ensured that the borehole seismic and the surface seismic at the borehole trajectory look as similar as possible. This was possible through quality control of the well log and seismic data, timing and log calibration, well tie location, seismic bandwidth and signal-to-noise ratio and the use of well tie diagnostics that underlie a successful close well tie. The data were processed to zero phase and the dominant loop in the resulting seismic wavelet was delayed and corresponds to an increase in P-impedance. The delay on the seismic data was removed and the wavelet converted to zero phase. The ties are generally good and accurate. With this success we were able to relate directly the horizons picked on the $3 D$ anisotropic seismic data to the well logs. We estimated the wavelets needed to invert the seismic data to impedance and rock property indicators. This was achieved by careful simultaneous analysis of the results at the wells to derive one average wavelet each for the near, mid and far angle stacks.
\end{abstract}

Keywords: Angle stacks, horizons, P-impedance, synthetic seismogram, wavelet,

\section{Introduction}

The field was discovered by well-002 which was drilled in 1992 and was initially covered in that same year by a 2D seismic survey that was reprocessed in 2005. Imaging of the crest of the structure remained very poor coupled with uncertainties about the lateral extent of the reservoirs,pinchout and fault positions. So, a new anisotropic 3D seismic data was acquired between 2008 and 2010 and processed in 2011. This data is reasonably good down to 2.5 seconds beyond which deeper events are poorly defined and discontinuous. Therefore well-to-seismic ties were performed to aid the interpretation of the seismic data as they allow horizons picked to be related directly to a well $\log$ and provide a means of estimating the wavelet needed to invert the seismic data to impedance and to rock property indicators.

The increasing application of 3D seismic surveys and reservoir geophysics to reservoir management has emphasized the importance of seismic-to-well ties and, with it, the accuracy of well ties. The prerequisite for a close tie between a well log synthetic seismogram and a seismic data volume are accurate sonic and density logs and good quality seismic data. Well-to-seismic tying corresponds to the process of reconciliation of the well and the seismic data. That means to find on the seismic image the position of geological markers determined at the well. Very often, this process is embedded in another exercise such as wavelet estimation for seismic reservoir characterization, because both processes are so closely related [1].

Well-to-seismic tie which is the best way to tie seismic data back to ground truth by comparison with well log data using synthetic seismogram is also widely used for seismic interpretation. The essence of the well tie is (1) to identify geological and seismic interfaces from the logs and core, (2) to measure the one way traveltime to these interfaces using down hole geophones, and (3) to use the polarity information from (1) and the timing information from (2) to identify the horizons on the zero phase processed seismic data [2].Also, wellto-seismic tie helps to produce wavelet for inversion for reservoir properties.

Additionally, when the final product from the seismic data processing is delivered in the depth domain, it provides very important seismic anisotropic information. The value of the well-to-seismic tie depends on the quality of the seismic data, well data and the time/depth relationship. The usual way to tie well information to seismic data in the depth domain is to convert them to time, tie them and convert them back to depth. However, this process can introduce additional uncertainty because the velocities used to transform each data set to time can be different. One of the most important variables affecting the well-to-seismic tie is the migration velocity, because incorrect velocities result in lateral and vertical reflection mispositioning. One factor that can significantly affect velocities is the presence of anisotropy. Incorrect accounting for anisotropy manifests itself as an incorrect vertical seismic velocity, causing the data to mistie[3].

Accurate well-to-seismic ties are fundamental to the interpretation of surface seismic data. A statement of well-to-seismic tie accuracy is essential to any attempt to quantify uncertainty in seismic lithological interpretation. It is worthy of note whether the data are processed to zero phase, whether the dominant loop in 
the resulting seismic wavelet is delayed, whether the loop corresponds to an increase or decrease in acoustic impedance. A well tie makes this correspondence clear and knowledge of the seismic wavelet is critical to inversion to impedance. The elements of the well-to-seismic tie include a broadband primaries synthetic seismogramconstructed from a calibrated P-impedance (AI) log is matched to a seismic trace segment. The synthetic seismogram is filtered to the bandwidth of the seismic data and time and phase shifted to match the seismic data. The filter that converts the broadband synthetic to the matched synthetic is the seismic wavelet.

\section{The study area}

Amangi Field is located $70 \mathrm{~km}$ northwest of Port Harcourt within licence OML 21 in the Greater Ughelliof the Niger Delta of southern Nigeria as shown in Fig. 1. The Niger Delta lies between latitudes $4^{\circ} \mathrm{N}$ and $6^{\circ} \mathrm{N}$ and longitudes $3^{\circ} \mathrm{E}$ and $9^{\circ} \mathrm{E}$.

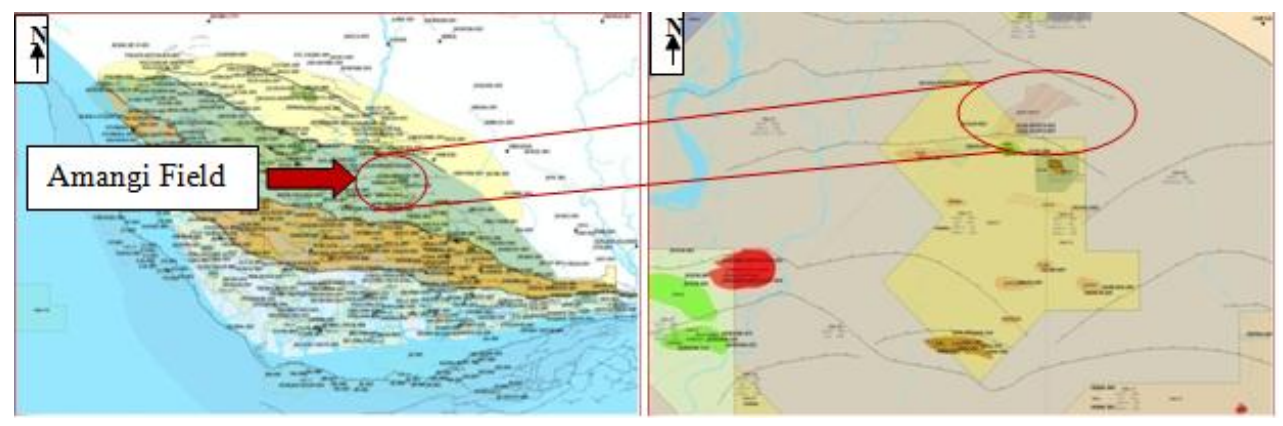

Figure 1. Map of the Niger Delta showing the study area. The encircled portion is the location of Amangi Field. (Source: Shell Petroleum Development Company of Nigeria Ltd.).

The Field is bounded to the north and south by large listric normal faults associated with gravity collapse in the delta. The Tertiary age siliciclastic deposits forming the Niger Delta are divided into three lithostratigraphic Formations: the Akata Formation, the Agbada Formation and the Benin Formation. The Agbada Formation makes up the majority of the hydrocarbon reservoirs of the Niger Delta including this field, and comprises alternating sandstone/shale bed sets interpreted to represent the delta front, distributor channels and the deltaic plain. The hydrocarbon bearing interval of the field is part of a succession of Tertiary proximal deltaic deposits separated by laterally extensive shale/shalyheterolithic packages that represent flooding episodes [4].

\section{Well log data}

The location of the six wells on the field is displayed in Fig. 2. Four of the wells are located in OML 21 while the rest two are in OML 53. The field is a unitized field. However, well data were available from five wells as shown in Table 1. The well log data availability summary for Amangi Field is presented in Table 1.

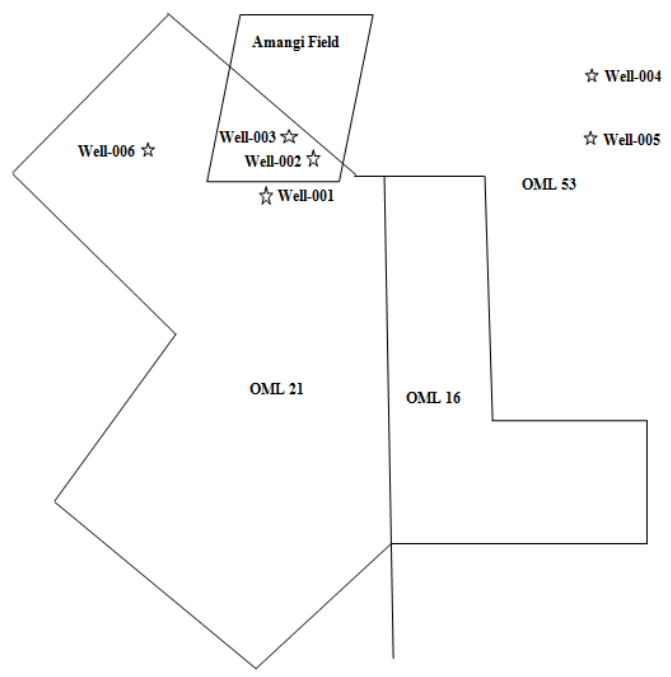

Figure 2.OML map of the study area showing the locations of the wells used in this study. Four out of a total of six wells are located in OML 21 whereas the rest two wells are sited in OML 53. 
Table 1. Some wells in Amangi Field showing suite of logs in each well. From the table only Well-002 has a complete suite of good quality logs in the area, needed for this work.

\begin{tabular}{|l|l|l|l|l|l|l|l|l|}
\hline Well & $\begin{array}{l}\text { GR } \\
(\mathbf{A P I})\end{array}$ & $\begin{array}{l}\text { CALL. } \\
(\text { inches }\end{array}$ & $\begin{array}{l}\text { RESIS. } \\
(\mathbf{\Omega} \text { m) }\end{array}$ & $\begin{array}{l}\text { DEN. } \\
\left(\mathbf{g} / \mathbf{c m}^{3}\right)\end{array}$ & $\begin{array}{l}\text { SONIC } \\
(\mu \mathrm{fs})\end{array}$ & $\begin{array}{l}\text { PRES. } \\
(\mathbf{p s i})\end{array}$ & FIT & Checkshot(ms) \\
\hline $\begin{array}{l}\text { Well- } \\
\mathbf{0 0 1}\end{array}$ & YES & YES & YES & NO & YES & NO & NO & YES \\
\hline $\begin{array}{l}\text { Well- } \\
\mathbf{0 0 2}\end{array}$ & YES & YES & YES & YES & YES & YES & YES & YES \\
\hline $\begin{array}{l}\text { Well- } \\
\mathbf{0 0 3}\end{array}$ & YES & YES & YES & YES & YES & YES & NO & NO \\
\hline $\begin{array}{l}\text { Well- } \\
\mathbf{0 0 4}\end{array}$ & YES & YES & YES & YES & YES & NO & NO & NO \\
\hline $\begin{array}{l}\text { Well- } \\
\mathbf{0 0 5}\end{array}$ & YES & YES & YES & YES & YES & NO & NO & NO \\
\hline
\end{tabular}

Fig. 3is the well logs from well-002 in the study area. The lithology classification is shown in track 7 in which sand is yellow and shale is green. Edited compressional sonic and shear sonic (tracks 3 and 4) and density $\log$ is intrack 14. Resistivity and porosity curves are in tracks 6 and 11, respectively. The gamma ray, caliper, neutron, neutron-density, water saturation, $\mathrm{V}_{\mathrm{p}}$, and $\mathrm{V}_{\mathrm{s}}$ curves are in tracks 2, 5, 8, 9, 10, 12 and 13 respectively. The measured depth and the two way travel time are recorded in track 1 . The numbering of the tracks is done from left to right.

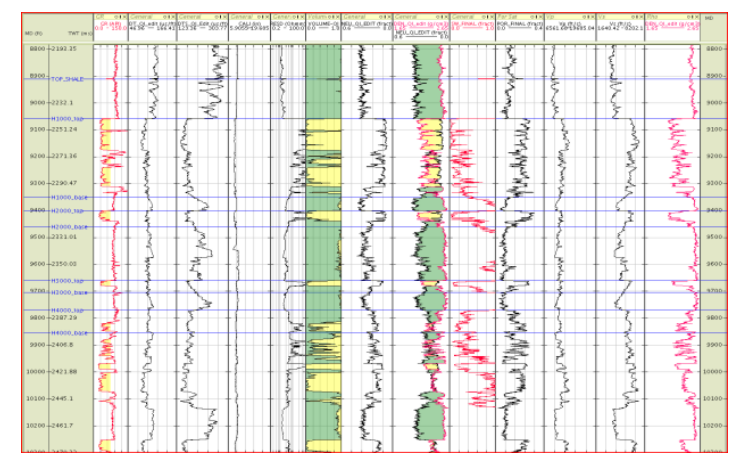

Figure 3.Typical log signatures of shales/sands section in the area of study as seen in well-002. Gamma ray, sonic, caliper, resistivity, volume shale, neutron, porosity, water saturation, $V_{p}, V_{s}$ and density logs from well-002 used in this study. The thick gas reservoirs are characterized by higher resistivities and neutron-density crossover.

\section{Methodology}

We adopted the approaches used by [5,6] andstretching/squeezing was avoided but the checkshot calibration, plus small manual bulk time shifts were relied upon to align the well log time-depth relationship to that of the seismic data.In this work we incorporate a rock physics model to assist in the mapping of the horizons and analyze rock properties. Since shales and their related rocks constitute a larger percentage of rocks in this area, they play a very important role in seismic wave propagation and fluid flow. Anisotropy from the earth formations that make velocities of wave propagation in each direction different ismainly caused by intrinsic anisotropy from shales. We first used seismic data only and is aimed at evaluating a preliminary zero phase wavelet whose amplitude spectrum is representative of the seismic data. Secondly, we then used both the well and seismic data to analyze the correlation between a synthetic trace computed from impedance log and portions of seismic traces surrounding the well [5].

\section{Fault analysis}

The existence of compartments in the H1000 and H4000 crestal areas is based on the interpretation of the well-002 well test. One of the faults is sealing at H4000 level (different fluid contacts in well-002 and well004) but not at H1000 level. H1000 hydrocarbons are trapped in a closure against the southern and southeastern faults. The crest is in the southeastern corner at approximately 2,590.80 m (8500 ft). The H1000 reservoir dips towards the northwest, with a dip of some $3.5^{\circ}$ across the hydrocarbon filled area, and steeper in the aquifer. 
The detailed delineation of the structure is currently improved by better imaging in the crestal areas at the south eastern and southern edges of the field, in the shadow zone of the large boundary faults. H4000 closure residing in the foot wall side of the southern and southeastern boundary faults. Three wells penetrate H4000; however gas was detected only by well-002. Well-005 is water bearing and well-004 has an oil-water contact. Fig.4 is the depth structure contour maps of the tops of the reservoirs.

The structure is an elongated rollover anticline bounded to the south and southwest by large boundary faults that throw down toward the south and southeast. Toward the north is a regional growth fault that joins ith the northeastern boundary fault to close the structure toward the east. It is a fault deep closure against a large growth fault which separates it from a neighbouring field.

Three H4000 structural realizations are built from the base case, minimum and maximum top structure maps and two isochrons. H4000 sands are interpreted to represent a series of channelized shoreface deposits (where channels are fluvial dominated). In H4200, a thick channel is interpreted as a tidal channel at well-002, but as a more fluvial dominated channel in well-005 (to the east) and at well-003 (to the west).
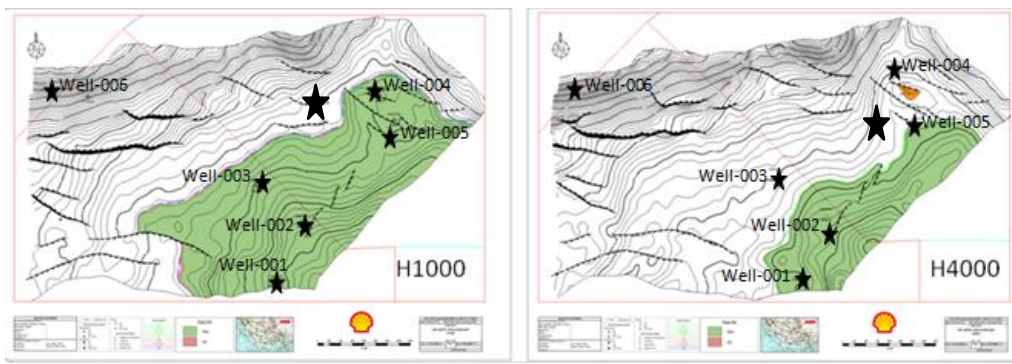

Figure 4.Depth structure contour maps of the tops of the gas reservoir sandstones $(\mathrm{H} 1000$ and $\mathrm{H4000})$ respectively, as interpreted from the $3 \mathrm{D}$ seismic data. Contour interval is $50 \mathrm{~m}$. The locations of seismic lines (in red) across the structure are indicated. The shaded areas (in green) are proven hydrocarbon filled areas. The structure also shows some major faults and drilled wells in the study area (Courtesy: SPDC, Nigeria Ltd.).

\section{Crossplots at the target horizons}

Fig.5shows crossplot of rock properties with lithology classification and anisotropy. We observe velocities change with respect to lithology, even in the same lithology which contains different clay contents. The horizons are at depths of $8865 \mathrm{ft}-9157 \mathrm{ft}$ and $2184 \mathrm{~ms}$ for the $\mathrm{H} 1000$ and $9577 \mathrm{ft}-9661 \mathrm{ft}$ and $2326 \mathrm{~ms}$ for the H4000.
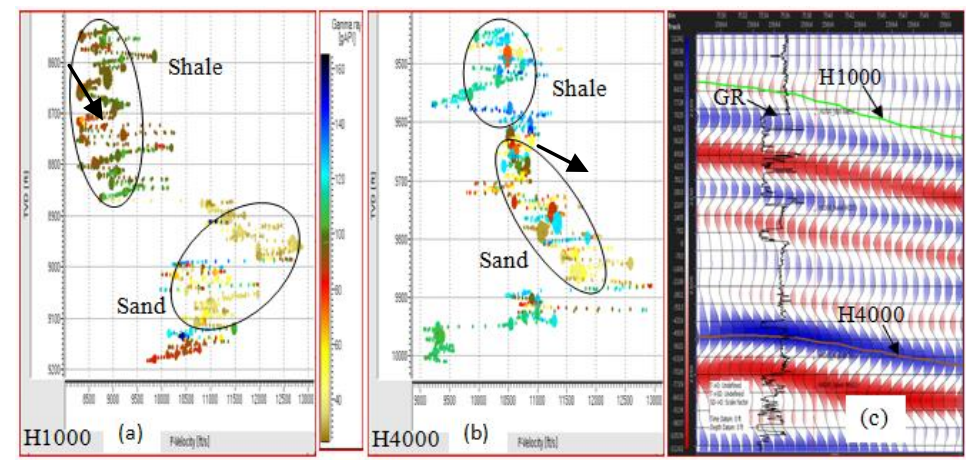

Figure5.(a) \& (b)show crossplots of well $P$-wave velocity versus depth in the target zones colour coded with gamma ray, showing the depths to the horizons and velocities of lithology. The seismic section (c) shows the seismic data with gamma ray and markers overlain and also showing the target horizons H1000 and H4000.

\section{Wavelet estimation}

The increasing use of 3D seismic data for quantitative reservoir characterization informs the crucial importance of a reliable well-to-seismic calibration. The single link existing between well data and seismic data is the wavelet; as a consequence, we are determined to carefully estimate the wavelet. Prior to the inversion, wavelets were estimated for each offset stack to enable the inversion to compensate for offset dependent phase, bandwidth, tuning and normal moveout (NMO) stretch effects which can affect the amplitude and phase spectra of the data. Separate wavelets were estimated for each angle stack as in $[7,5,6]$. The available well control was used in wavelet estimation and incorporated AVO modelling to properly account for AVO effects. The angle 
dependent seismic wavelets were estimated by doing wavelet shaping between modelled logs and angle stacks. In doing this, we effectively tied the wavelet offset analysis to real log measurements.

The sonic $\log$ s were calibrated using well checkshot data to ensure that the time-depth relationship matches that of the seismic data. The calibrated sonic logs were then combined with the density logs to calculate impedance and reflectivity series for each well location. An initial zero phase wavelet, with amplitude spectrum was calculated from the square root of the amplitude spectrum of the autocorrelation of each trace, and then extracted from the seismic data. This wavelet was used to construct synthetic seismograms at each well location as per the convolution model of the seismic trace[8]. Applying alterations to the wavelet amplitude and phase spectra (see each well-to-seismic tie), such that a maximum correlation is found between the synthetic seismograms and seismic traces, allows a deterministicwavelet to be estimated at each well location.

\section{Synthetic seismogram generation}

Every seismic interpretation project needs to begin with an attempt to tie seismic reflectors to geologic units via synthetic seismograms. The first goal in working with seismic data is to ensure that the borehole seismic and the surface seismic at the borehole trajectory look as similar as possible. This achieved, we can then tightly link the surface seismic to events at the borehole and subsequently correlate structures and evaluate properties between wells.

The seismic data near each well were fitted by iteratively convolving the P-wave impedance logs with the near angle wavelet estimated (Fig. 9) to produce the synthetic predicted traces.Similarly, this approach was adopted using the estimated mid and far angles wavelets to produce the respective synthetic predicted traces. Where no borehole seismic data were available, synthetic seismograms were constructed from impedance and density logs. The phase was obtained by forcing the well derived synthetic seismogram to match the seismic, thus assuming the well log provides ground truth.

\section{Results and discussions}

We selected two wells, well-002 from OML 21 and well-004 from OML 53 to perform the well-toseismic ties and compared them. The first three panels from the left contain the wavelet, seismic and the synthetic seismograms respectively. The fourth panel from the left is a correlation panel showing the degree of correlation between the surface seismic trace segment in the second and the synthetic seismogram in the third panel from the left, which is a measure of the goodness-of-fit. The fifth panel from the left contains the inverted P-impedance section while the sixth panel from the left is the drift indicating the extent of stretching/squeezing applied to the data. Generally no stretching and squeezing was made on the data as could be seen on the panel. Finally, the gamma ray log (GR - red colour) and the P-sonic log (DT - purple colour) are displayed in the last panel on the extreme right.

Adjacent to each well-to-seismic tie is a display of the wavelet amplitude and phase spectra showing the zero phase wavelets and an average wavelet. The residuals (not shown) are the difference between the seismic trace and its synthetic seismogram, indicating how good the fit is. We also computed the normalized mean square error in the synthetic seismogram and the average phase error within the seismic bandwidth from the "predictability" $\mathrm{P}$, a measure of the goodness-of-fit defined as:
$\mathrm{P}$
$=$
1
(energy
in
the
residuals/trace

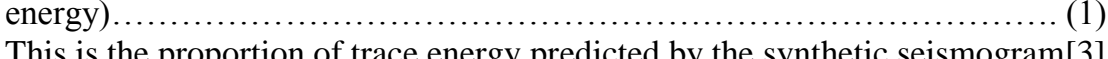

Accurate well-to-seismic tie exercise wereperformed in this workusing the near, mid and far substack volumes of the new anisotropic 3D seismic data. The wavelets extracted from the seismic at the well locations were used to generate the synthetics, by convolving the wavelet with the reflection coefficient series of the Earth. The synthetics agreed very well with the seismic. The wavelet at each well was found to be very similar, close to zero phase and the data bandwidth was determined to be $10-60 \mathrm{~Hz}$ as shown in the extreme left panel of Figs.6, 7 and8. The seismic is shown in the first panel close to the wavelet whereas the synthetic is in the panel immediately after the seismic. The next panel contains the correlation and tops. This correlation shows the degree of agreement between the seismic and the synthetic. The next panel following displayed the P-impedance obtained from the simultaneous inversion of the surface seismic data, overlain by the P-impedance obtained by inverting the seismic data measured at the well. These also showed a good match. A panel showing the degree of stretching/squeezing was also included. Finally, the panel on the extreme right displayed the gamma ray, Psonic and P-impedance logs extracted from the inverted P-impedance. This panel also displayed the reservoirs of interest in depth (TVDss) in the study area.

The well was a vertical well and mildly overpressured. At the H1000 level, the work resulted in a confident tie at well-002, well-003, well-004, and well-005 and at well-006. At well-004, the synthetic seismogram can be tied to the seismic in two different ways, each of which is compatible with a defendable scenario of field wide horizon interpretation. At well-002, the base of the H4000 can be confidently tied, but the 
local match at the top of the H4000 is poor. Well-006 does not penetrate the H4000. The H1000 has a good well-to-seismic tie at well-002, which defined where the top and base of the H1000 fall on the seismic, with the assumption of a roughly constant H1000 thickness. The base case scenario is depicted by the blue picks, following the top and base of the blue-red doublet (Fig.8), which suggests thinning (pinchout) towards the northeastern part of the field. But atwell-004, there is a significant H1000 thickness again, which means the $\mathrm{H} 1000$ has to thicken in the direct vicinity of the well, possibly across a major fault in the area.

The seismic-to-well tie of the top of the H4000 is poor at both well-004 and well-002 (Fig.8). Using the better constrained H1000 top and H4000 base seismic-to-well ties as analogue, the H4000 top/base case pick was defined to be at the zero crossing, from a soft to hard interface. The pick uncertainty increases in areas of poor seismic resolution; particularly in the middle of the field, northwards towards areas of growth faulting and around the fault shadow zones (Fig. 4). The estimated wavelet amplitude and phase spectra and the well-toseismic tie for each offset stack are shown for wells well-002 and well-004, in Figs. 6, 7 and 8.

Fig. 6 is well-to-seismic tie for the near angle stack and shows a reasonably good correlation because as we can see, most major reflection events can becorrelated between the seismic and the synthetic. The interpreted seismic horizons (H1000 and H40000) are displayed in red and green on the well-to-seismic ties.
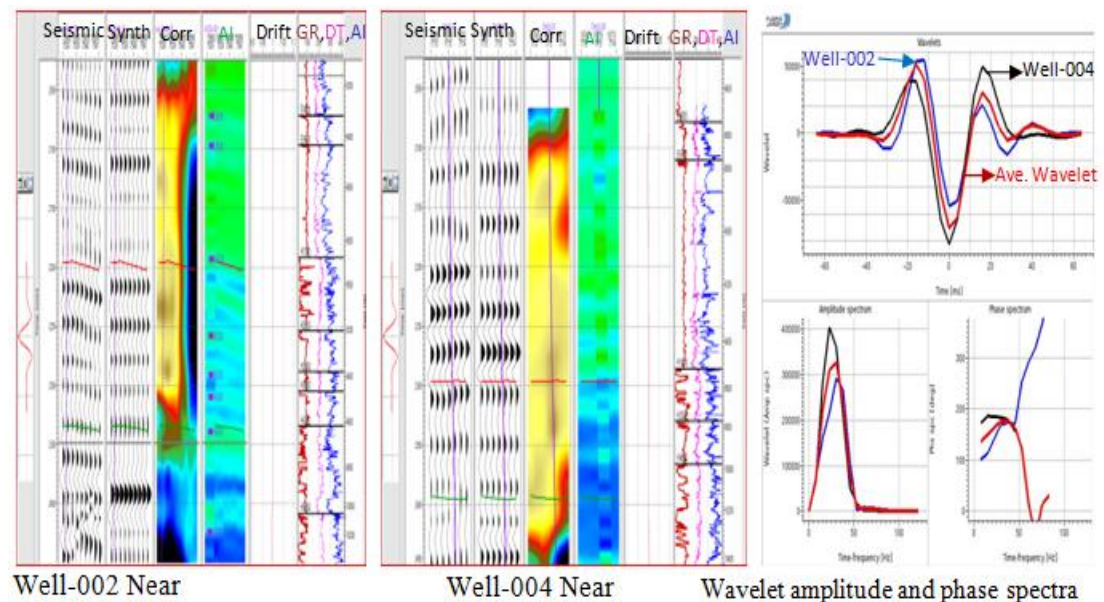

Figure 6. Well-to-seismic ties of the near stacks $\left(0^{\circ}-10^{\circ}\right)$ for well-002 and well-004 with horizons and gamma ray, $P$-sonic and $P$-impedance logs and wavelet amplitude, phase and spectra. There is reasonable tie between synthetic and seismic data with a cross correlation factor of 0.7 .

The well-to-seismic tie gives a correlation coefficient of $70 \%$ over the 420 mslogging interval. The time domain wavelet estimated from thiswell-to-seismic tie is shown at the extreme right. The very high correlationcoefficient indicates that the data is high quality andthat the tie is sound. The resulting estimated wavelet is highlydesirable from an interpretation perspective as acoustic impedance boundariesin this case would correspond to the dominant peaks andtroughs in the seismic data.

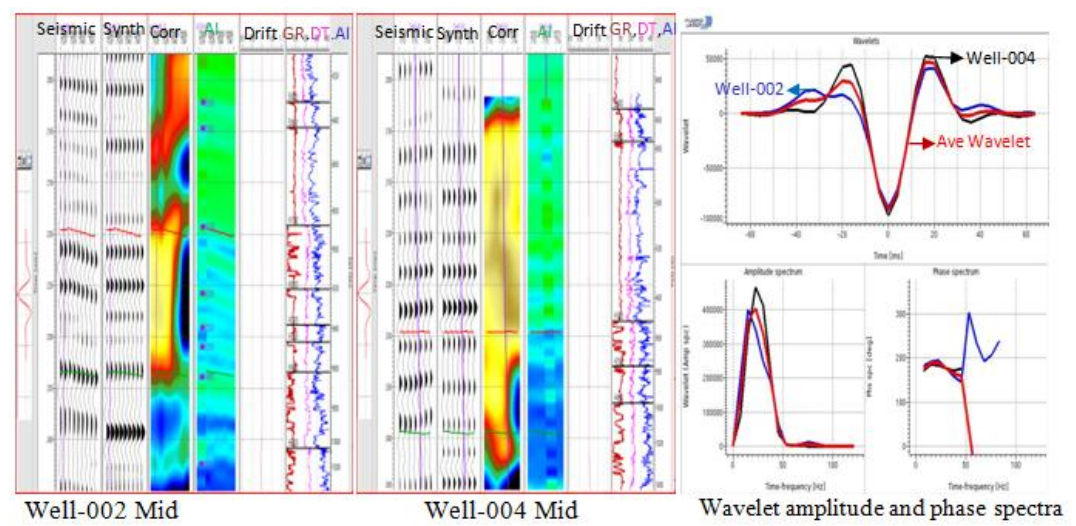

Figure 7. Well-to-seismic ties of the mid stacks $\left(11^{\circ}-20^{\circ}\right)$ for Well-002 and Well-004 with horizons, gamma ray, $P$-sonic and $P$-impedance logs and wavelet amplitude, phase and spectra. Reasonable tie between well and seismic data with a cross correlation factor of 0.6 . 
The near angle tie is very good. The far angle well-to-seismic tie is poor. Often times, however, the quality of the far offset well tie is significantly worse than the near as we can see in Fig. 8. The correlation coefficient drops by an order of magnitude when we look at the far stack well tie. A couple of causes for the difference in the quality of the near stack and far stack well-to-seismic ties could be postulated. The far offset data could be of poorer quality than the near offset data. Another potential reason for the difference could be that our modelling algorithms were not including all the relevant physics. As offsets increase, incidence angles also increase, and the physics becomes more complex. Converted waves, interbed multiples, AVO, attenuation, anisotropy, and NMO stretch are some of the more significant effects that can complicate analyses of far offset data.

Angle dependent reflectivity is highly influenced by the shear wave impedance contrast at an interface. So, another possible explanation for poor far offset well-to-seismic ties is that the measured shear velocity log is of poor quality or is not measuring the seismically relevant quantity [8].

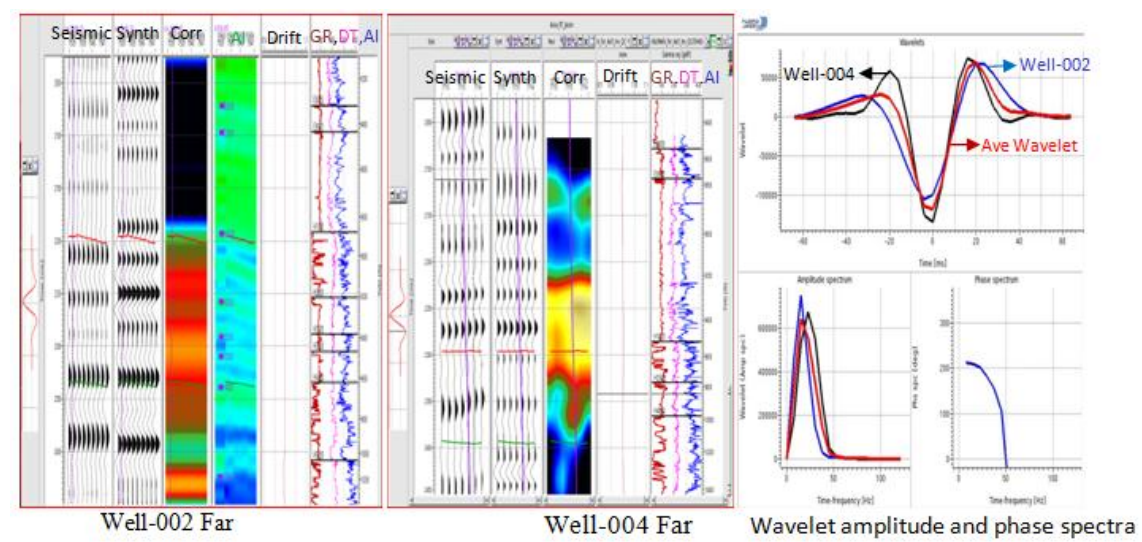

Figure 8. Well-to-seismic ties of the far stacks $\left(21^{\circ}-30^{\circ}\right)$ for Well-004 and Well-004 with horizon, gamma ray, P-sonic and P-impedance logs and wavelet amplitude, phase and spectra. Reasonable tie between well and seismic data with a cross correlation factor of 0.4 .

The estimated wavelet amplitude and phase spectra for the well-to-seismic ties are displayed alongside the ties. The wavelets are for both well-002 and well-004 near, mid and far stacks and their average wavelets. The wavelets estimated for each offset stack was near zero phase, varying mostly in their frequency content. A good well tie is necessary to reduce uncertainties in the estimated wavelet. Figs.6, 7 and 8 showed the well-toseismic ties for the estimated wavelets corresponding to the near, mid and far angle sections at well-002 and well-004 respectively. A best tie was achieved on a common angle section and ideally the near angle stack in this study.This was possible because at the near offsets, the physics is relatively simple, and an adequate wellto-seismic tie is often achieved by simply convolving a wavelet with a reflectivity series.

\section{Final estimated wavelets}

The wavelet estimation process is crucial to any seismic inversion since the shape of the wavelet used may strongly influence the details of the resulting reservoir model. Wavelet analysis was performed by computing a filter that best shapes the well log reflection coefficients to the input seismic data at the well locations. The phase of the seismic data (as a function of frequency) is found from the inverse of this filter [9]. The well positioning and wavelet extraction were performed in the reservoirs' level. For our simultaneous inversion for P-impedanceand S-impedance, a separate wavelet analysis was done for each of the three angle stacks (near, mid, and far angles).

Fig.9 shows the three estimated seismic average wavelets for the three angle stacks. We determined the wavelets for the well-to-seismic tie for all suitable wells. After the generation of the wavelets, cross correlation and validation between wells and inversion tests were used to select one optimum (average) wavelet to use in the inversion. Therefore, we choose the waveform and length carefully, and maximized the cross correlation and also minimized the relative misfit between synthetic and real seismic data. Wavelet extraction was performed around each well using the edited well logs and checkshot calibrated time/depth function. During this process, the well-to-seismic tie was refined with respect to the synthetic seismogram generated from the well log data and the wavelet. This step helped tie the seismic data to the synthetic seismogram generated from the well data. The wavelets combine the averaged dominant phase with the bandwidth of the data. Since the signals change significantly with offset in the target window, the three wavelets were used for the prestack simultaneous inversion. 
For each angle window, the seismic data are matched to the appropriate impedance logs at the wells as the wavelets are estimated. Wavelet estimation was performed by computing a filter that best shapes the well $\log$ reflection coefficients to the input seismic data at the well locations. By wavelet estimation, the inverted amplitudes of the seismic data are calibrated to the control provided by the impedance logs at the wells [7,9].

A separate wavelet analysis was performed for each of the three angle stacks (near, mid, and far angles) for the simultaneous inversion for P and S impedances. For each angle window, the seismic data are matched to the appropriate impedance $\operatorname{logs}$ at the wells as the wavelets are estimated. The estimated wavelets, with amplitudes representative of each angle stack, are input to the inversion. Minor phase differentials were accounted for in the wavelet estimation and inversion, so there is confidence in the tie between the Pimpedanceand S-impedancesections. Note the similarity in shapes and frequency of the wavelets as theylook very much alike since they have the same phase, and almost the same amplitude.

But originally, we observed that the shapes of the extracted wavelets at each well location were quite different, and their phases were not close to zero. This means that the wavelets varied spatially within the 3D migrated volume. This spatial variation is unlikely to be seen due to the well data because the well logs were edited and calibrated. Therefore, in this study, to correct for the space variant component we applied the space adaptive wavelet processing mechanism to equalize the nonzero phase wavelets to become zero phase. Sonic logs provide ground truth data on formation velocities for seismic imaging and inversion and for generating synthetic seismograms that are subsequently used in seismic ties.

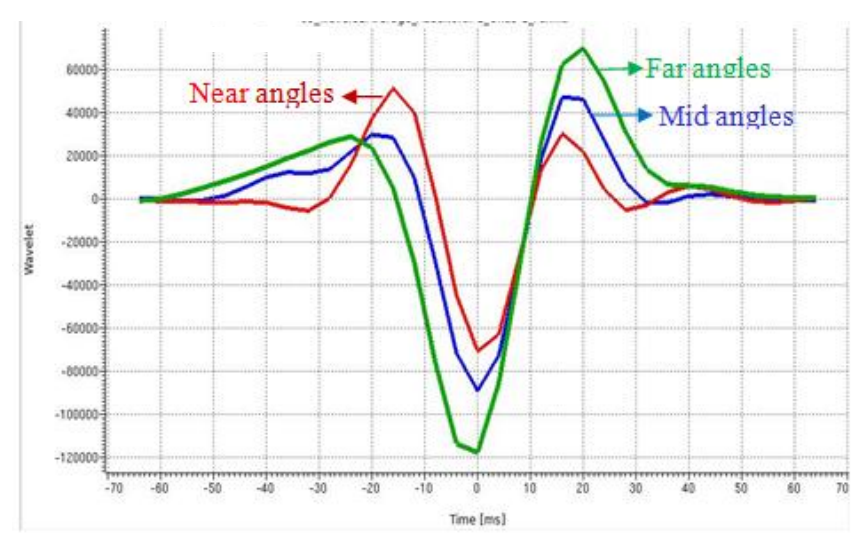

Figure 9. Final estimated near, mid and far seismic average wavelets for the three migrated angle stacks used in the inversion. Amplitude increases with increasing angle but the frequency content is fairly constant. These wavelets, with amplitudes representative of each angle stack were inputted directly into the inversion algorithm.

\section{Conclusion}

Understanding the relationship between the reservoirs and their fluid properties measured in the wells and their expression in the seismic data is crucial to making needed predictions of the reservoirs and their fluid properties away from the wells based on the seismic response.Well-to-seismic ties are thus, a fundamental part of seismic data analysis. In both processing and interpretation, well ties provide an important link between the data we record and the physics we believe to be occurring.

The well-to-seismic ties for the near and mid angle stacks are reasonably good at the zones of interest and are essential to increase thecredibility of seismic interpretation. The events on the processed seismic data are conventionally identified from well logs via the construction of a synthetic seismogram that is the best match, in some sense, to the processed data at the well position, and is simply the convolution of a wavelet with the normal incidence reflection coefficient series. This approach was sufficient to produce well-to-seismic ties with high coefficients of correlation.

The work reveals the importance of quantitative approach to well-to-seismic ties that result in measures of the wavelet accuracy and the synthetic seismogram to seismic goodness-of-fit.The synthetic seismograms derivedto ensure a good match often require timeshifts that are inconsistent with the checkshot data at the wells. The events on the processedseismic data may be identified from well logs simply by theirpolarity and timing. It follows that events can then be followedon the seismic data from one well to another, with confidence, and the seismic data can be interpreted for stratigraphy.

Seismic processors should run well-to-seismic ties during processing as this could bring considerable improvement to seismicdata quality and interpretation. The determination of stratigraphy from seismic data requires precise knowledge of the wavelet, thus with appropriate data processing we could benefits direct identification of seismic events from well logs on the basis of timing and polarity. Also, we could achieve a 
good correlation of seismicevents from well to well, and reliable interpretation of stratigraphy.Our approach has allowed us to tie the wells in the south and northeastern parts of the field without changing the phase of the wavelet at the wells and to map the stratigraphy on these lines. We have also obtained average wavelets for the three angle stacks, which shall be inputted for impedance inversion in subsequent analysisof the field data for reservoir properties.

\section{Acknowledgements}

Theauthorsare thankful to the Shell Petroleum development Company (SPDC) of Nigeria, for granting permission to publish this work. We also thank Dike S. Robinson,Francesca I. Osayande,PrahladBasak, Lucky M. Omudu, and Temitope J. Jegede for their immense contributions to make this work. Also, many thanks to the University Liaison of the SPDC and all who supported us by various contributions by way of comments and counsels that made this work a success.

\section{References}

[1]. P. Allouche, P. Thore, and T. Monnerie, Towards a better seismic to well tie in complex media. International Exposition and Annual Meeting, Houston, Society of Exploration Geophysicists, 2009, 1870 - 1874.

[2]. A. Ziolkowski, J. R. Underhill, and R. G. K. Johnston, Wavelets, well ties, and the search for subtle stratigraphic traps.Geophysics, 63(1), 1999, $297-313$.

[3]. R. White, and Simm, R. Tutorial: Good practice in well ties. First Break,21, 2005, $75-83$

[4]. K. C. Short, and A. J. Stauble, Outline of geology of Niger Delta. TheAmerican Association of Petroleum Geologists Bulletin, 51(5), 1967, $761-799$.

[5]. 7. J. Pendrel, and P. van Riel, Effect of well control on constrained sparse spike seismic inversion.Canadian Society of Exploration Geophysicists, Recorder, 2000, $18-26$.

[6]. P. Y. Dequirez, F. Fournier, C. Blanchet, T. Feuchtwanger, and D. Torriero, Integrated stratigraphic and lithologic interpretation of the east-senlac heavy oil pool. Society of Exploration Geophysicists, Expanded Abstracts, 1995, 104-107.

[7]. N. Lucet, P. Y. Dequirez, and F. Cailly, Well-to-seismic calibration: a multiwell analysis to extract one single wavelet, Society of Exploration Geophysicists, Expanded Abstracts, 2000, 1- 4.

[8]. J. Pendrel, and P. van Riel, Effect of well control on constrained sparse spike seismic inversion.Canadian Society of Exploration Geophysicists, Recorder, 2000, 18 - 26.

[9]. D.Gratwick, and C. Finn, What's important in making far stack well-to-seismic ties in West Africa?The Leading Edge,24(7), 2005, $739-745$

[10]. G. B. Madiba, G. B. and G. A.McMechan, G. A., Processing, inversion, and interpretation of a 2D seismic data set from the North Viking Graben, North Sea,Geophysics,68(3), 2003, 837 - 848. 